\title{
Ocena jakości warstw wierzchnich kompozytowych napawanych GMA w sposób zrobotyzowany na powierzchniach krzywek przesiewacza koksu ze stali HTK $900 \mathrm{H}$
}

\author{
Evaluation of the quality of composite surface layers \\ produced by robotic GMA cladding on cams \\ of coke screening plant made of $\mathrm{HTK} 900 \mathrm{H}$ steel
}

\section{Streszczenie}

Przedmiotem badań była analiza wpływu parametrów procesu zrobotyzowanego napawania GMA drutem rdzeniowym EnDOtec D048 o średnicy 1,6 mm powierzchni roboczych krzywek przesiewacza koksu ze stali trudnościeralnej HTK $900 \mathrm{H}$ na jakość, kształt i odporność na zużycie ścierne napoin. Próby napawania prowadzono z zastosowaniem robota spawalniczego Reis SRV6 oraz synergicznego urządzenia spawalniczego TotalArc 5000. Napoiny próbne wykonane drutem rdzeniowym EnDOtec D048 wykazują cechy materiału kompozytowego z węglikami wolframu osadzonymi w osnowie metalicznej. Rozmieszczenie węglików na przekroju poprzecznym napoiny jest niejednorodne, gdyż gromadzą się one głównie w pobliżu linii wtopienia napoin. Twardość metalu osnowy przekracza 52 HRC, przy twardości podłoża ze stali HTK $900 \mathrm{H}$ w zakresie 33 do 35 HRC. Pomimo pęknięć poprzecznych, napoiny wykazują o rząd wielkości wyższą odporność na zużycie ścierne typu metal-metal w próbie ball-on-plate.

Słowa kluczowe: napawanie, warstwy wierzchnie, warstwy kompozytowe, napawanie zrobotyzowane GMA

\section{Abstract}

The subject of the study was to analyse the influence of process parameters of robotic GMA cladding, by cored wire EnDOtec D048 having a diameter of 1,6 mm, of cams working surfaces of coke screening plant made of HTK $900 \mathrm{H}$ wear resistant steel on the quality, shape and abrasive wear resistance of test surface layers. The test of cladding were performed by means of a welding robot Reis SRV6 and a synergic welding machine TotalArc 5000 . The test surface layers produced by the cored wire EnDOtec DO 48 exhibit characteristics of composite material with tungsten carbides embedded in the metal matrix. Distribution of carbides on the crosssection of surface layers is inhomogeneous, because the carbides accumulate near the fusion line. Hardness of the metallic matrix exceeds $52 \mathrm{HRC}$ and the hardness of the substrate of HTK $900 \mathrm{H}$ steel is in the range of 33 to $35 \mathrm{HRC}$. Although transverse cracks, the surface layers exhibit an order of magnitude higher resistance to the metal-metal wear type during the ball-on-plate tests.

Keywords: cladding, surface layers, composite layers, robotic GMA cladding

\section{Wstęp}

Proces zużycia powierzchni i krawędzi roboczych narzędzi oraz ruchomych części maszyn połączonych węzłami kinematycznymi jest zjawiskiem naturalnym i nieuniknionym. Prowadzi ono jednak do systematycznego spadku właściwości użytkowych, jak również sprawności i parametrów pracy. Ponadto silna tendencja do ograniczania emisji oraz energochłonności maszyn i urządzeń poprzez wzrost ich wydajności, sprawności przy jednoczesnej poprawie paramentów użytkowych (tzw. downsizing) powoduje, że warunki pracy narzędzi i części maszyn są coraz trudniejsze. Z drugiej strony dążenie do zwiększenia niezawodności i trwałości narzędzi oraz maszyn i urządzeń prowadzi do poszukiwania nowych i zaawansowanych materiałów inżynierskich. Nowe materiały muszą sprostać coraz trudniejszym, a często wręcz sprzecznym wymaganiom właściwości użytkowych części maszyn i narzędzi, wynikającym z trudnych i złożonych warunków pracy oraz złożonych mechanizmów zużycia. Jednym z przekładów zaawansowanych materiałów o szczególnych właściwościach są materiały kompozytowe typu MMC (Metal Matrix Composite), czyli kompozyty na osnowie metalicznej. Kompozyty tego typu łączą zalety i właściwości metalicznej osnowy oraz osadzonych w niej cząstek niemetalicznych takich jak węgliki, azotki, tlenki lub borki, czy też złożone związki niemetaliczne, np. węglikoazotki.

Dr inż. Aleksander Lisiecki, mgr inż. Wojciech Nowak - Politechnika Śląska, dr inż. Agnieszka Kurc-Lisiecka - Wyższa Szkoła Biznesu w Dąbrowie Górniczej, mgr inż. Grzegorz Waląg - Progresja.

Autor korespondencyjny/Corresponding author. alisiecka@wsb.edu.pl 


\section{Przebieg i wyniki badań}

Celem badań była analiza wpływu parametrów zrobotyzowanego napawania GMA drutem rdzeniowym EnDOtec D048 o średnicy 1,6 mm powierzchni roboczych krzywek przesiewacza koksu ze stali trudnościeralnej HTK $900 \mathrm{H}$ na jakość i kształt oraz odporność na zużycie ścierne napoin próbnych (tabl. I-III). Próby napawania zrobotyzowanego wykonano na stanowisku badawczym wyposażonym w robota spawalniczego Reis SRV6 oraz urządzenie spawalnicze TotalArc 5000 (rys. 1). Napoiny próbne wykonywano ruchem prostoliniowym na płaskiej powierzchni krzywki stalowej oraz na krawędzi roboczej krzywki (rys. 2). W celu doboru zakresu parametrów napawania wykonano wstępne próby napawania z zastosowaniem programu synergii dla drutu D048 o średnicy 1,6 mm (program nr 56), które wykazały, że poprawny kształt napoin i stabilny przebieg procesu napawania zapewnia napawanie łukiem pulsującym z prędkością $5 \mathrm{~mm} / \mathrm{s}$. W związku z tym właściwe napoiny próbne wykonano łukiem pulsującym przy stałej prędkości napawania $5 \mathrm{~mm} / \mathrm{s}$ oraz nominalnych natężeniach prądu napawania 250A (napoina N1 i N2, rys. 2a), 300A (napoina N3, rys. 2a) oraz 200A (napoina N4, rys. 2a). Jako gaz osłonowy zastosowano mieszankę $\mathrm{M} 21\left(\mathrm{Ar}+\mathrm{CO}_{2}\right)$, zalecaną do napawania drutem D048, przy natężeniu przepływu $16 \div 18 \mathrm{l} / \mathrm{min}$. Przed napawaniem powierzchnię krzywek czyszczono mechaniczne. Próby napawania wykonano bez podgrzewania wstępnego. Napoiny próbne poddano badaniom wizualnym, penetracyjnym za pomocą penetrantu barwnego, a następnie wycięto próbki do badań metalograficznych i pomiarów mikrotwardości na przekrojach poprzecznych napoin. Badania odporności na zużycie ścierne wykonano płaskiej, szlifowanej powierzchni lica napoin próbnych metodą ball-on-plate za pomocą testera Tribometer CSM Instruments. Jako przeciwpróbkę zastosowano

Tablica I. Skład chemiczny nominalny oraz twardość stopiwa drutu rdzeniowego EnDOtec D048 [2]

Table I. The nominal chemical composition and hardness of the deposit of cored wire EnDOtec DO48 [2]

\begin{tabular}{|c|c|c|c|c|c|}
\hline \multicolumn{3}{|c|}{ Skład chemiczny [\% wag.] } & \multicolumn{2}{|c|}{$\begin{array}{c}\text { Twardość Rockwella } \\
\text { HRC }\end{array}$} \\
\cline { 3 - 4 } & Osnowy & węglików \\
\hline Si & $\mathrm{Mn}$ & WC & Fe & \multirow{2}{*}{$55 \div 60$} & 2400 \\
\hline 0,1 & 0,2 & 50 & reszta & & \\
\hline
\end{tabular}

Tablica II. Skład chemiczny nominalny stali trudnościeralnej HTK $900 \mathrm{H}[3]$

Table II. The nominal chemical composition of wear resistant steel HTK $900 \mathrm{H}[3]$

\begin{tabular}{|c|c|c|c|c|c|c|c|}
\hline \multicolumn{7}{|c|}{ Skład chemiczny [\% wag.] } \\
\hline $\mathrm{C}$ & $\mathrm{Si}$ & $\mathrm{Mn}$ & $\mathrm{Cr}$ & $\mathrm{Mo}$ & $\mathrm{Ni}$ & $\mathrm{S}$ & $\mathrm{P}$ \\
\hline 0,18 & 0,45 & 1,5 & 1,0 & 0,4 & 0,3 & 0,01 & 0,025 \\
\hline
\end{tabular}

Tablica III.Właściwości mechaniczne stali trudnościeralnej HTK 900H [3]

Table III. Mechanical properties of wear resistant steel HTK 900H [3]

\begin{tabular}{|c|c|c|c|}
\hline $\begin{array}{c}\text { Wytrzyma- } \\
\text { tość na } \\
\text { rozciąganie, } \\
\text { Rm [MPa] }\end{array}$ & $\begin{array}{c}\text { Granica } \\
\text { plastyczno- } \\
\text { ści, Re [MPa] }\end{array}$ & $\begin{array}{c}\text { Wydłużenie, } \\
\text { A5 [\%] }\end{array}$ & $\begin{array}{c}\text { Twardość } \\
\text { Brinella HB }\end{array}$ \\
\hline $1100 \div 1250$ & $900 \div 1000$ & $10 \div 12$ & $360 \div 400$ \\
\hline
\end{tabular}

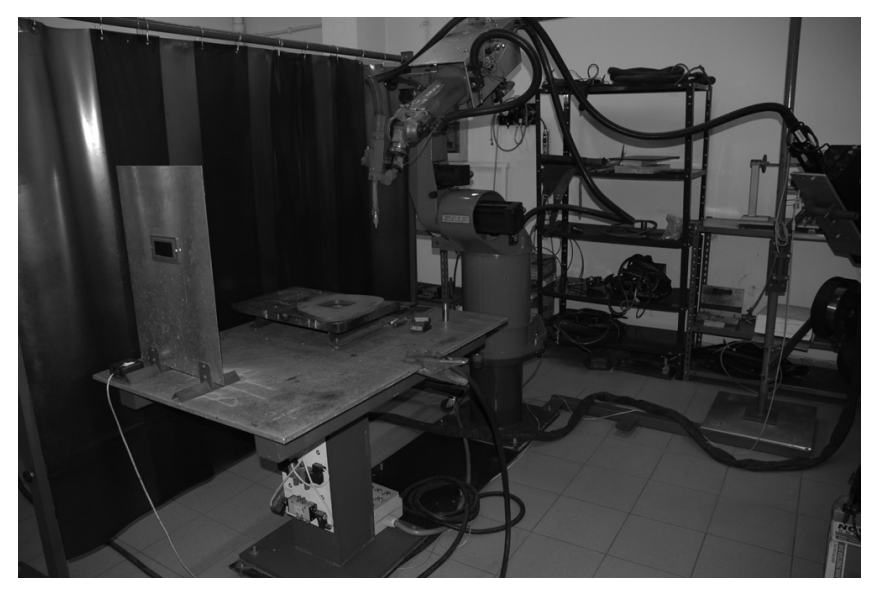

Rys. 1. Widok zrobotyzowanego stanowiska badawczego wykorzystanego do napawania krzywek przesiewacza koksu

Fig. 1. A view of robotic experimental stand used for cams cladding of coke screening plant
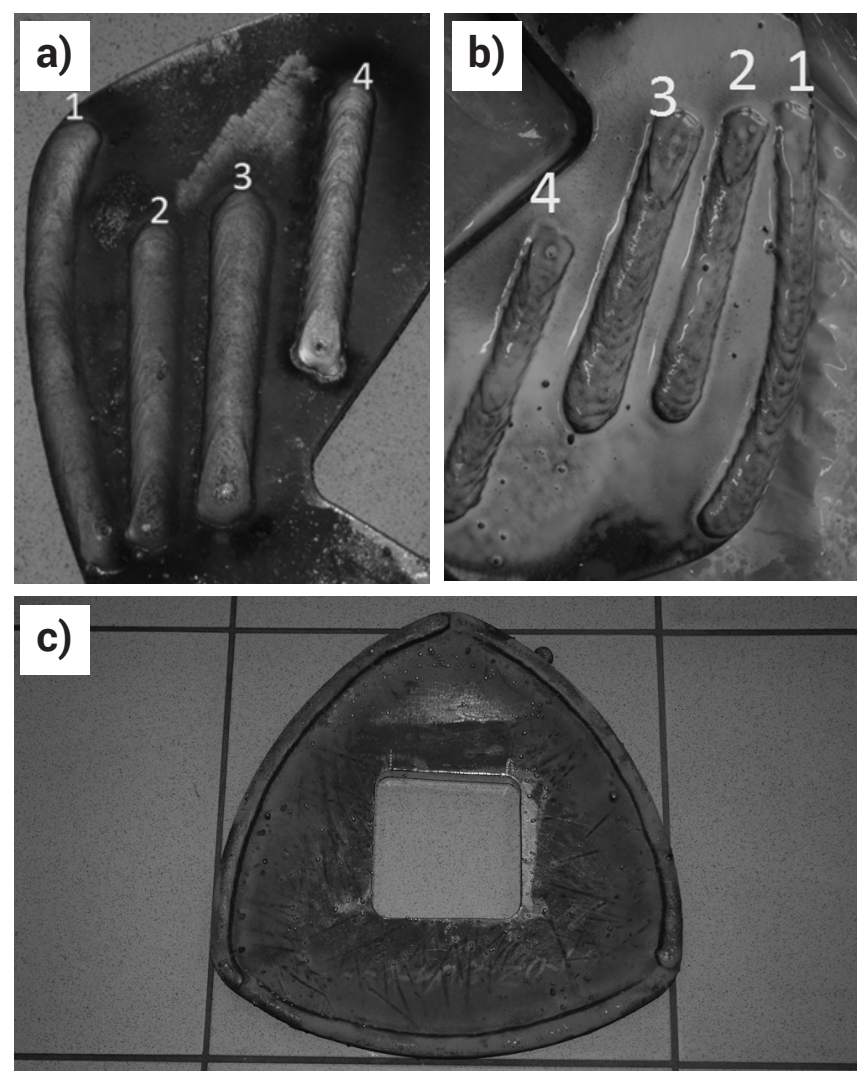

Rys. 2. Widok napoin próbnych wykonanych na powierzchni krzywki przesiewacza koksu bezpośrednio po napawaniu (a), podczas badań penetracyjnych (widoczne pęknięcia poprzeczne na powierzchni lica) (b) oraz widok krzywki z napawanymi powierzchniami roboczy$\mathrm{mi}$ - natężenie prądu napawania 250A, (c)

Fig. 2. A view of test clads produced on the surface of the cam directly after cladding (a), during the penetrant testing (clear transverse cracks on the face of clads) (b) and a view of the cam of coke screening plant with clads produced on the working surfaces - cladding current 250A, (c)

kulkę o średnicy $6 \mathrm{~mm}$ z tlenku glinu $\left(\mathrm{Al}_{2} \mathrm{O}_{3}\right)$. Siła docisku kulki do badanej powierzchni wynosiła $10 \mathrm{~N}$, a prędkość przesuwu $10 \mathrm{~mm} / \mathrm{s}$. Kulka była przemieszczana ruchem posuwisto-zwrotnym na odcinku $4 \mathrm{~mm}$, przy całkowitej drodze tarcia równej $250 \mathrm{~m}$. Następnie badano głębokość i kształt profilu ścieżki wytarcia za pomocą profilometru stykowego Sutronic 25 firmy Taylor Hobson. Jako miarę odporności na zużycie ścierne przyjęto objętość wytartego materiału (objętościowy ubytek materiału). Po określeniu wpływu parametrów napawania na właściwości napoin próbnych wykonano dwa komplety krzywek przeznaczone do badań 
eksploatacyjnych w rzeczywistych warunkach pracy. Krzywki napawano przy parametrach, które umożliwiały poprawne formowanie napoiny na krawędzi roboczej krzywki (rys. 2c).

\section{Analiza wyników badań}

Badania wizualne, jak również badania penetracyjne napoin próbnych wykonanych na krzywce przesiewacza koksu ze stali trudnościeralnej HTK $900 \mathrm{H}$ ujawniły szereg pęknięć poprzecznych na powierzchni lica napoin (rys. 2b). Pęknięcia te występują na powierzchni wszystkich napoiny próbnych, jednak największą liczbę pęknięć stwierdzono w przypadku napoiny N3 wykonanej przy najwyższej wartości prądu napawania $300 \mathrm{~A}$, a tym samym najwyższej energii liniowej $(13,9 \mathrm{~kJ} / \mathrm{cm})$. Badania metalograficzne i obserwacje makro oraz mikroskopowe wykazały, iż napoiny próbne posiadają strukturę kompozytową z węglikami wolframu WC osadzonymi w osnowie metalicznej (rys. 3). Napoiny posiadają regularną linię wtopienia, a szerokość strefy wpływu ciepła SWC nie przekracza 4,0 mm w przypadku napoiny wykonanej z najwyższą energią liniową. Wzdłuż linii wtopienia widoczne są ziarna kolumnowe oraz dendrytyczne. Udział materiału rodzimego w napoinach próbnych wykonanych na płaskiej powierzchni krzywki wynosił $24 \div 24,5 \%$ w przypadku napoin wykonanych przy natężeniu prądu odpowiednio 300 i 250 A oraz 16,3\% w przypadku napoiny wykonanej przy najniższym natężeniu prądu $200 \mathrm{~A}$. Z kolei w przypadku napoiny wykonanej na krawędzi roboczej udział materiału rodzimego wynosił ok. $16 \%$, co było spowodowane odmiennymi warunkami cieplnymi napawania i kształtem krawędzi krzywki (rys. 2). Badania mikroskopowe ujawniły również liczne mikropęknięcia napoin głównie w pobliżu linii wtopienia. Mikropęknięcia usytuowane są zarówno wzdłuż linii wtopienia, jak również prostopadle do niej. Większość z nich to pęknięcia transkrystaliczne, które przebiegają przez osnowę metaliczną oraz przez węgliki wolframu WC (rys. 3). Węgliki wolframu osadzone w osnowie posiadają nieregularny kształt, a największe z nich mają wielkość nawet $250 \div 300 \mu \mathrm{m}$. Węgliki rozmieszczone są nierównomiernie na przekroju poprzecznym napoin. Największa liczba węglików o największej wielkości znajduje się w pobliżu linii wtopienia. Powodem tak silnej segregacji węglików jest ich duży ciężar właściwy $\left(15,6 \mathrm{~g} / \mathrm{cm}^{3}\right)$, prawie dwukrotnie wyższy od stali, co powoduje grawitacyjne opadanie węglików na dno jeziorka spawalniczego, pomimo ruchów konwekcyjnych ciekłego metalu w jeziorku. Ponadto na zdjęciach mikrostruktur napoin można wyróżnić dwie charakterystyczne strefy o różnej barwie. W jaśniejszej strefie przyległej do linii wtopienia koncentracja węglików jest znacznie większa, niż w strefie o ciemniejszej barwie (rys. 3). Granica pomiędzy węglikami i osnową metaliczną w strefie o jaśniejszej barwie jest wyraźna i wąska, z kolei w strefie ciemniejszej granica pomiędzy węglikami i osnową jest szersza z obszarem przejściowym utworzonym w wyniku częściowego nadtopienia węglików i wzajemnej dyfuzji składników z nadtopionych w węglików wolframu oraz osnowy. Tak, więc można przyjąć, że strefa ta jest wzbogacona w węgiel i wolfram z częściowo nadtopionych węglików WC. Jednak szczegółowa identyfikacja struktur wymaga badań składu chemicznego i fazowego napoin próbnych. Pomiary mikrotwardości na przekroju poprzecznym napoin wykonywano jedynie w osnowie, pomiędzy węglikami wolframu, gdyż twardość węglików wolframu jest bardzo wysoka w zakresie 2000 do 2500 HV. Wyniki pomiarów wskazują, że mikrotwardość osnowy metalicznej jest ponad dwukrotnie wyższa od mikrotwardości materiału

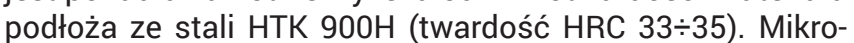
twardość osnowy badanych napoin jest zbliżona i mieści się w zakresie od 600 do 750 HV0,5 (twardość HRC ponad 52).
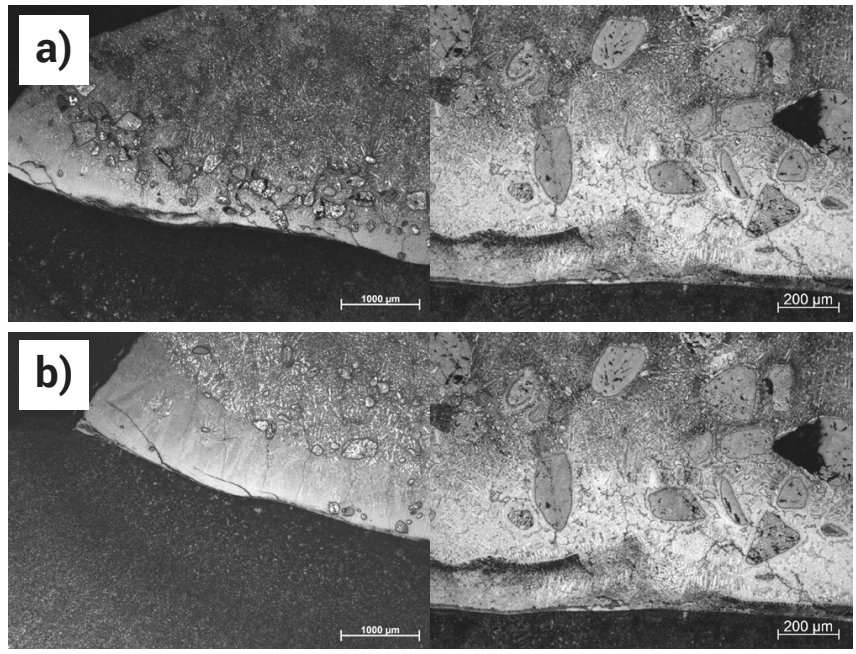

Rys. 3. Makro i mikrostruktura napoin próbnych wykonanych drutem rdzeniowym EnDOtec DO48 na powierzchni krzywki ze stali HTK 900H; a) napoina N1 (prąd napawania $250 \mathrm{~A}$ ), b) napoina N3 (prąd napawania $300 \mathrm{~A}$ )

Fig. 3. Macro and microstructure of test clads produced by the cored wire EnDOtec DO48 on the surface of cam made of HTK $900 \mathrm{H}$ steel; a) clad N1 (cladding current $250 \mathrm{~A}$ ), b) clad N3 (cladding current $300 \mathrm{~A}$ )

a)

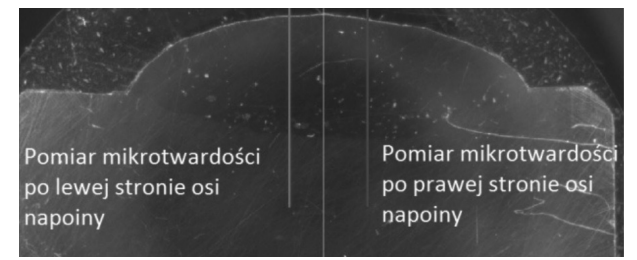

b)

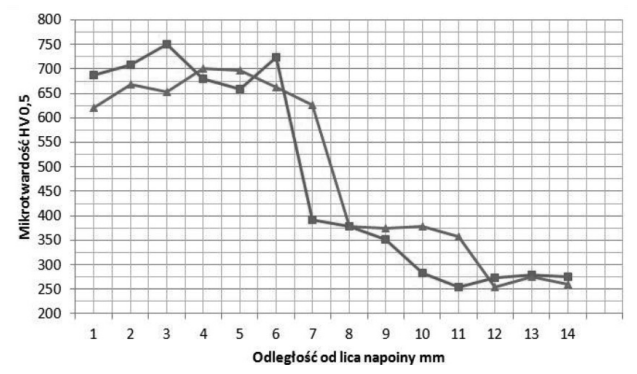

c)

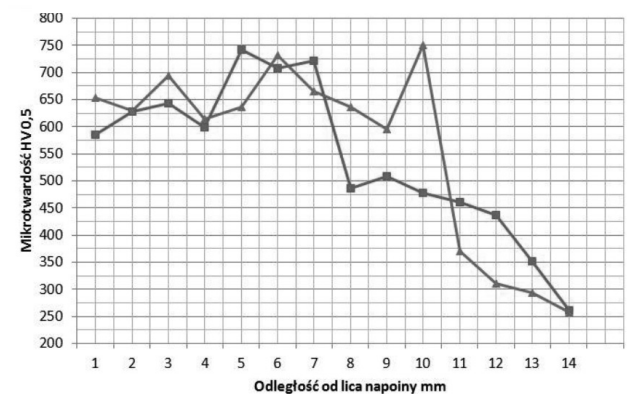

d)

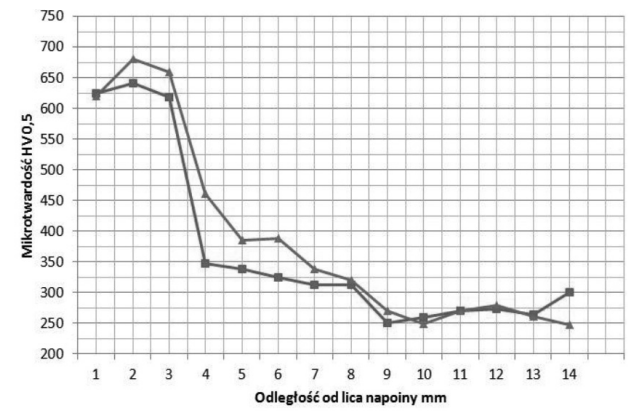

Rys. 4. Sposób pomiaru mikrotwardości na przekroju poprzecznym napoin próbnych (a) oraz rozkład mikrotwardości; b) napoina N2, c) napoina N3, d) napoina N4

Fig. 4. Sposób pomiaru mikrotwardości na przekroju poprzecznym napoin próbnych (a) oraz rozkład mikrotwardości; b) napoina N2, c) napoina N3, d) napoina N4 
Z kolei w SWC mikrotwardość obniża się stopniowo od ok. 350-450 HV0,2 w pobliżu linii wtopienia do mikrotwardości materiału podłoża, tj. ok. 300 HV0,2 (rys. 4). Badania odporności na zużycie ścierne wykonane metodą ball-onplate wykazały, że największy ubytek materiału występuje w przypadku próbki ze stali trudnościeralnej HTK $900 \mathrm{H}$. W tym przypadku szerokość ścieżki wytarcia była równa aż 1,1 mm, przy głębokości sięgającej $50 \mu \mathrm{m}$, a ubytek

a)

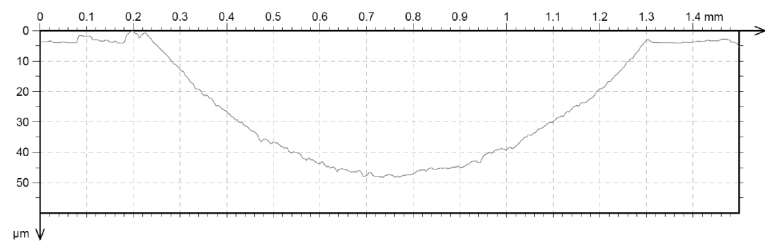

b)

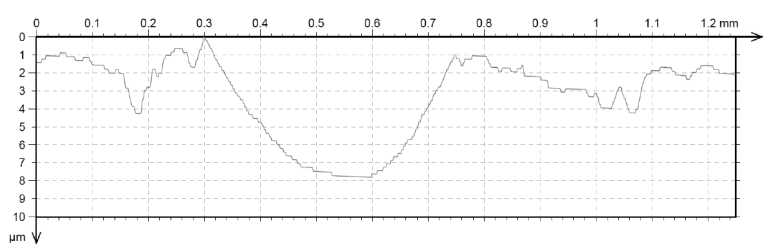

Rys. 5. Profil ścieżki wytarcia na powierzchni próbki ze stali HTK $900 \mathrm{H}(\mathrm{a})$ oraz napoiny próbnej N2 (b)

Fig. 5. A profile of the wear track on the surface of HTK $900 \mathrm{H}$ steel sample (a) and the test clad N2 (b) objętości próbki wyniósł 0,1464 $\mathrm{mm}^{3} \mathrm{w}$ warunkach, w jakich wykonano próby ścierania (rys. 6). Z kolei w przypadku napoin próbnych ubytek objętości mieścił się w zakresie od 0,008 do $0,0147 \mathrm{~mm}^{3}$, a więc stopień zużycia powierzchni napoin był dziesięciokrotnie niższy w porównaniu do próbki ze stali trudnościeralnej. Szerokość ścieżki wytarcia nie przekraczała 0,3 $\div 0,4 \mathrm{~mm}$, przy głębokości nie większej niż $8 \mu \mathrm{m}$ (rys. 5).

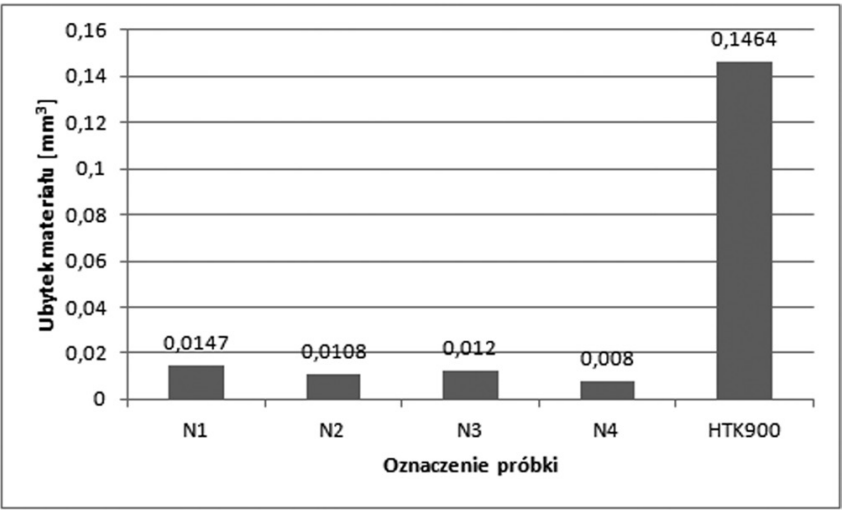

Rys. 6. Wyniki badań odporności na zużycie ścierne stali HTK 900H oraz napoin próbnych metodą ball-on-plate

Fig. 6. The results of abrasive wear resistance study of $\mathrm{HTK} 900 \mathrm{H}$ steel and the test clads determined by the ball-on-plate method

\section{Podsumowanie}

Badania napoin wykonanych drutem rdzeniowym Endotec DO48 w procesie zrobotyzowanego napawania GMA krzywki przesiewacza koksu wykazały, że napoiny posiadają strukturę kompozytową z węglikami wolframu osadzonymi w osnowie metalicznej. Z uwagi na duży ciężar właściwy węgliki wolframu opadają na dno jeziorka spawalniczego w trakcie napawania, co powoduje, że ich koncentracja jest najwyższa w pobliżu linii wtopienia. Napoiny próbne wykonywane bez podgrzewania wstępnego wykazywały znaczną skłonność do pękania w badanym zakresie parametrów. Powodem wysokiej skłonności do pękania jest wysoka mikrotwardość osnowy napoin kompozytowych w zakresie 600 do 750 HV0,5. Jednak pomimo pęknięć poprzecznych lica napoin oraz mikropęknięć występujących w pobliżu linii wtopienia, odporność na zużycie ścierne napoin próbnych jest dziesięciokrotnie wyższa w porównaniu do stali trudnościeralnej HTK $900 \mathrm{H}$.

\section{Literatura}

[1] A. Lisiecki, A. Majowski, T. Gorzelik, J. Jarek, P. Gorzela, A. Kurc-Lisiecka: Sterowanie jakością i trwałością części roboczych brykieciarki napawanych metodą MMA w procesie wytwarzania brykietów stalowych. Biuletyn Instytutu Spawalnictwa, Nr 4, s. 8-15, 2015.
[2] https://www.castolin.com/product/endotec-do48.

[3] http://www.htk.com.pl/hut_trans.php?main/blachy_trudnoscieralne. 